\title{
Effluent Treatment Facility Peroxide Destruction Catalyst Testing
}

Prepared for the U.S. Department of Energy

Assistant Secretary for Environmental Management

Project Hanford Management Contractor for the

U.S. Department of Energy under Contract DE-AC06-96RL13200

FLUOR

P.O. Box 1000

Richland, Washington 


\section{Effluent Treatment Facility Peroxide Destruction Catalyst Testing}

Document Type: TI

Program/Project: WM

D. L. Halgren

Fluor Hanford, Inc.

Date Published

July 2008

Prepared for the U.S. Department of Energy

Assistant Secretary for Environmental Management

Project Hanford Management Contractor for the

U.S. Department of Energy under Contract DE-AC06-96RL13200

\section{FLUOR.}

P.O. Box 1000

Richland, Washington
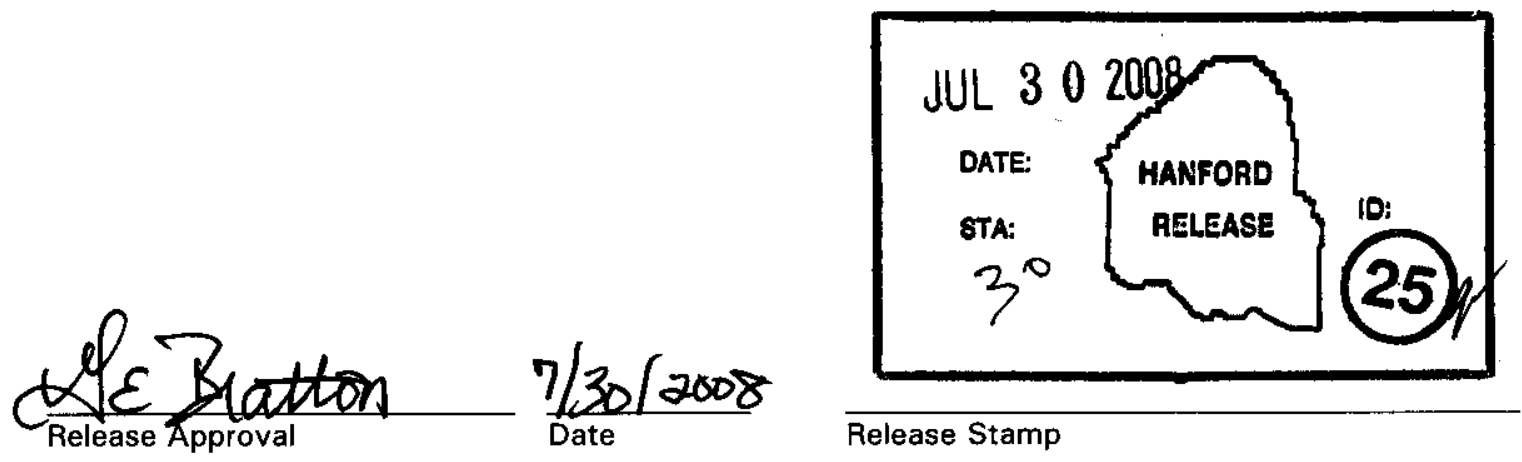

Release Stamp

\section{Approved for Public Release;}

Further Dissemination Unlimited 
HNF-38408

Revision 0

TRADEMARK DISCLAIMER

Reference herein to any specific commercial product, process,

or service by trade name, trademark, manufacturer, or

otherwise, does not necessarily constitute or imply its

endorsement, recommendation, or favoring by the United

States Government or any agency thereof or its contractors or subcontractors.

This report has been reproduced from the best available copy.

Printed in the United States of America

Total Pages: $\quad \mid 1$ 


\section{CONTENTS}

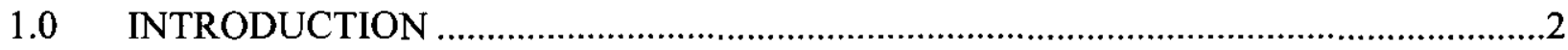

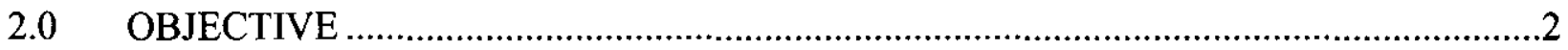

$3.0 \quad$ TEST DESCRIPTION

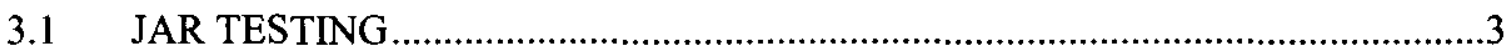

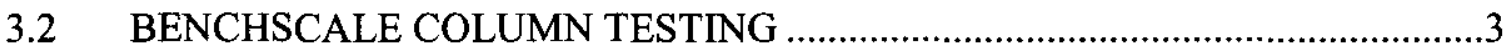

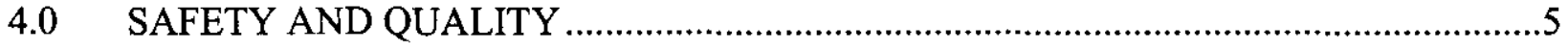

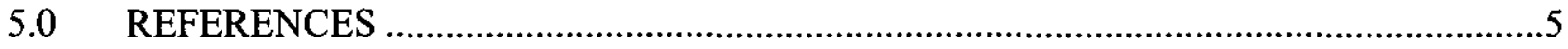

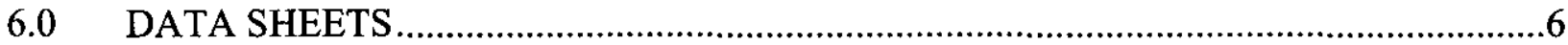

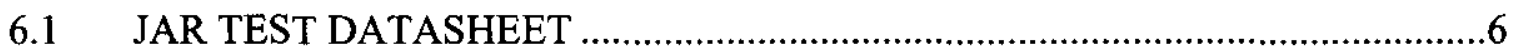

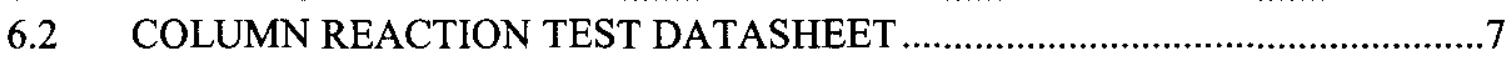

6.3 CATALYST DURABILITY TEST DATASHEET ........................................8

\section{TRADEMARK INFORMATION}

Carulite ${ }^{\circledR}$ is a registered trademark of Carus ${ }^{\circledR}$ Corporation, Peru, IL, USA

CHEMet $B$ and VACUettes $(B$ are registered trademarks of CHEMetrics $\otimes$, Inc., Calverton, VA, USA

Centaur $B$ is a registered trademark of Calgon Carbon Corporation, Burlingame, CA, USA

EM Quant $\circledast$ is a registered trademark of EMD Chemicals $®$ Inc., Frankfurter StraBe 250 D64293 Darmstadt FED REP GERMANY

BASFB is registered trademark of BASF Aktiengesellschaft Carl-Bosch-Strasse 38 Ludwigshaf FED REP GERMANY D-67063

Johnson Matthey $\otimes^{\circledR}$ is a registered trademark of Johnson Matthey Public Limited Company CORPORATION UNITED KINGDOM 2-4 Cockspur Street, Trafalgar Square London UNITED KINGDOM SW1Y 5BQ 


\subsection{INTRODUCTION}

The 200 Area Effluent Treatment Facility (ETF) main treatment train includes the peroxide destruction module (PDM) where the hydrogen peroxide residual from the upstream ultraviolet light/hydrogen peroxide oxidation unit is destroyed. Removal of the residual peroxide is necessary to protect downstream membranes from the strong oxidizer. The main component of the PDM is two reaction vessels utilizing granular activated carbon (GAC) as the reaction media. The PDM experienced a number of operability problems, including frequent plugging, and has not been utilized since the ETF changed to groundwater as the predominant feed. The unit seemed to be underperforming in regards to peroxide removal during the early periods of operation as well. It is anticipated that a functional PDM will be required for wastewater from the vitrification plant and other future streams. An alternate media or methodology needs to be identified to replace the GAC in the PDMs.

\subsection{OBJECTIVE}

This series of bench scale tests is to develop information to support an engineering study on the options for replacement of the existing GAC method for peroxide destruction at the ETF. A number of different catalysts will be compared as well as other potential methods such as strong reducing agents. The testing should lead to general conclusions on the viability of different catalysts and identify candidates for further study and evaluation.

\subsection{TEST DESCRIPTION}

Benchscale testing of catalyst performance will be done on two levels. Initially small amounts of each available catalyst will be tested in a jar test to obtain basic reaction kinetic data. To evaluate catalyst behavior, both kinetic and physical, in a flow-through bed situation a small test column will be used. Test parameters will be scaled from the existing PDM columns for initial testing. Changes may be made for subsequent tests as information on the performance of the different catalysts is acquired. The GAC used in the existing system will be put through the testing to provide a comparison point for the other catalysts.

Samples of the following catalysts have been obtained for testing.

- Manganese dioxide on alumina - Sud-Chemie T-2525, CDS

- Manganese dioxide/copper oxide - Carus $^{\circledR}$ Carulite ${ }^{\circledR} 200,4$ x 8

- Peroxide alumina - BASF DD-6, 28 x 48

- Palladium (1\%) on silica - Johnson Matthey@ lot P-919, 8 x 18

- Platinum (1\%) on silica - Johnson Matthey® lot P-915, $8 \times 18$

- Hydrous Ferric Oxide - Molecular Products O-P Hydrogen Catalyst

- $\mathrm{GAC}$ - Calgon Carbon Centaur $\Re, 12$ x 40 
Additional catalysts types may be tested as they are identified and obtained. Other candidate materials include silver, catalase, and reducing agents such as sodium sulfite. The amount of catalyst available will vary based on the amount available as samples from the catalyst manufacturers. Sample sizes for the precious metal catalysts are expected to be small. Additional catalyst may be purchased if the initial testing identifies a catalyst as a preferred candidate and more material is needed for further testing. Adjustments to amounts described in this test plan may be made to make sure all candidate catalysts are tested on the same basis.

In the PDM three foot diameter, 15 foot tall columns are filled to the 6 foot level with the GAC. The columns were designed to operate in an upflow expanded bed mode with a maximum design flow rate of 90 gallons per minute (gpm) resulting in a superficial velocity of $12.7 \mathrm{gpm} / \mathrm{ft}^{2}$ and contact time of 3.6 minutes. At a more typical process flow of $50 \mathrm{gpm}$ per column gives flow parameters of $7.0 \mathrm{gpm} / \mathrm{ft}^{2}$ and contact time of 6.4 minutes. These process parameters will also be used as starting points for test parameters. Other flows, catalyst volumes, and configurations may tested as needed to complete the data gathering.

\subsection{JAR TESTING}

In this basic jar test the prescribed amount of catalyst will be washed with tap water to remove fines and wet the catalyst. It is anticipated in order to accommodate the smallest sample size that testing will begin with at least 40 milliliters $(\mathrm{mL})$ of each sample in a small beaker. The sample will be covered with at least $100 \mathrm{~mL}$ of water, adjusted to the target $\mathrm{pH}$. For all tests the typical target $\mathrm{pH}$ will be approximately 5 to reflect the ETF process $\mathrm{pH}$ at the PDMs. Hydrogen peroxide will be added to a 200 parts per million (ppm) target concentration. Samples will be taken and analyzed for peroxide concentration at least every three minutes until the reaction has progressed to a minimal peroxide concentration.

The time and concentration will be recorded on the datasheet and used to calculate reaction rate constants as the reaction is expected to approximate a first order reaction. Reaction rates for each of the candidate catalysts can be compared to establish which catalyst would provide the best kinetic performance. In previous GAC jar tests the derived reaction rates did not seem to scale to the large column configuration with acceptable accuracy, likely due to flow distribution, channeling, and other factors. The jar testing should, however, provide adequate comparative results to leading to a determination of the best candidates for larger scale testing.

If there is sufficient sample the catalyst and peroxide solution quantity and can be increased to give a more repeatable result that would not be as affected by the removal of some solution for the peroxide concentration samples. This test may be repeated with agitation to determine if there is a rate improvement with mixing.

\subsection{BENCHSCALE COLUMN TESTING}

The benchscale column apparatus consists of a clear one inch diameter PVC pipe with the fittings to connect it to a feed and drain line as shown in Figure 1. The peroxide solution will be fed from a feed tank by a peristaltic pump with a rotameter in-line. Provisions will be made for sampling from the feed and discharge lines at the column. Materials for a two inch column are available if a larger benchscale column is needed for additional testing.

Three different tests will be performed using the column. These tests will be used to evaluate reaction kinetics, flow configuration, and catalyst durability. 
Figure 1

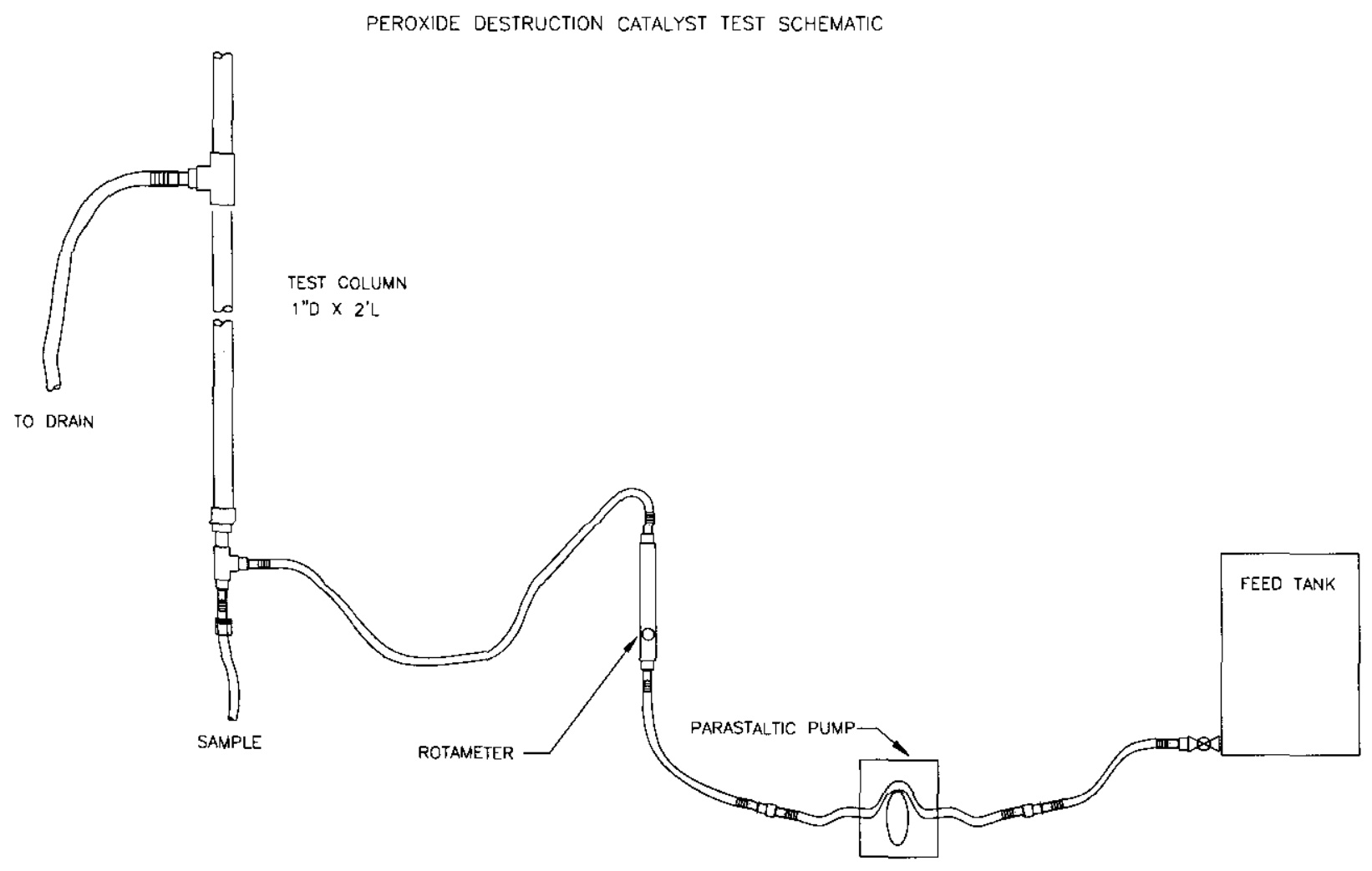

For testing peroxide destruction kinetics in an upflow column the prescribed amount of catalyst, by weight, will added to the column. Water adjusted to the target $\mathrm{pH}$ and at the target influent peroxide concentration will be pumped through the column at the flow setpoint. The influent peroxide target will be at least $100 \mathrm{ppm}$ but some series of tests may use a higher setpoint. Flow setpoints will be used to simulate the full-scale PDM superficial velocity and contact time. Samples will be taken of the column effluent at a regular interval during the test. The interval length will depend on the test flow rate. A sample of the feed will also be taken at the end of the run to determine if there has been significant peroxide concentration degradation in the feed solution over the test period. The same set of conditions will be used for at least one test of all candidate catalysts to provide a consistent data point. From the recorded data the reaction rate constants will be calculated for comparison between catalysts and with the results of the jar test. See the example datasheet in Section 6.0 for all data to be recorded. During the test the degree of bed expansion will be measured and recorded as well as any observations on media carryover.

The upflow expanded operation mode of PDM operation is advantageous for removal of the gas bubbles generated by the reaction and increased contact surface area of the fluidized media but may contribute to the fines generation problem. In this test the test column influent and effluent tubing connections will be switch to operate the column in a downflow configuration. The same test procedure with the same parameters as the previous test will then be performed. The results will be compared with the upflow results to determine any reduction of effectiveness with the 
downflow configuration. The column will be observed closely for any impacts caused by gas buildup or binding. The same datasheet as for the first test will be used.

Catalyst durability will be assessed by determining the amount of fines generation during upflow operation. The minimum flow rate used will provide $12.7 \mathrm{gpm} / \mathrm{ft}^{2}$ superficial velocity. Higher flows may be used if needed to get sufficient catalyst movement. All catalysts will be tested under the same set of parameters. Three full stream samples will be taken at equal time intervals and sent to the lab for total suspended analysis. The results will allow comparison of catalyst degradation and fines generation, which has been a significant part of the GAC use problem at the ETF.

For all testing the hydrogen peroxide concentration will be determined using visual colorimetric test kits. The CHEMet $® \mathrm{~K}-1550$ and VACUettes $® \mathrm{~K}-1550 \mathrm{D}$ kits from CHEMetrics $\circledast$ provide the necessary quantification range for this testing. EM Quant $\$$ Peroxide Test indicator strips used by operations for residual peroxide surveillance are also available for a quick indication. As depicted in Figure 1 the flow will be measured using a rotameter with several flow ranges available. Other parameters like temperature and $\mathrm{pH}$ will be measured using existing lab instruments.

\subsection{SAFETY AND QUALITY}

The most signification hazard involved in this testing is the handling of corrosive chemicals such as sulfuric acid. The hydrogen peroxide $(3 \%)$ used is sufficiently dilute that is does not pose a significant hazard. Hazards are mitigated by using available controls such as the fume hood, proper lab procedures and techniques, and the use of personal protective equipment (PPE). Plant procedure LEF-OP-007 specifies the PPE to be used for these chemicals. All chemicals and materials purchased for use in this testing will have MSDSs entered into the facility book and included in the facility inventory.

There are no specific quality assurance requirements related to this testing. Equipment will be verified in working order prior to testing and operated according to manufacturer instructions where applicable. There will be a functional check of the $\mathrm{pH}$ meter prior to each round of testing with calibration on an as needed basis. Hydrogen peroxide concentration visual colorimetric readings will generally be made by two individuals to reduce the likely of interpolation error.

\subsection{REFERENCES}

HNF-SD-LEF-TI-004, Rev. 0, Activated Carbon Testing for the 200 Area Effluent Treatment Facility, R. N. Wagner, January 17, 1997.

LEF-OP-007, Rev. B-0, Personal Protective Equipment, March 24, 2005. 


\subsection{DATA SHEETS}

\subsection{JAR TEST DATASHEET}

Peroxide Destruction Catalyst Jar Test

Date

Catalyst

Catalyst Amount

Beaker Size

$\mathrm{Gr}$ $\mathrm{mL}$

Water Volume $\mathrm{mL}$

$\mathrm{pH}$

H2O2 target Ppm

Stirring $\mathrm{Y} / \mathrm{N}$

Stir Setting

\begin{tabular}{|c|c|c|}
\hline Time (min) & $\mathrm{H} 2 \mathrm{O} 2$ Conc (ppm) & $\begin{array}{c}\text { In } \\
\mathrm{C}_{\mathrm{t}} / \mathrm{C}_{0}\end{array}$ \\
\hline 0 & & \\
\hline 3 & & \\
\hline 6 & & \\
\hline 9 & & \\
\hline 12 & & \\
\hline 15 & & \\
\hline 18 & & \\
\hline 21 & & \\
\hline 24 & & \\
\hline 27 & & \\
\hline 30 & & \\
\hline
\end{tabular}

Temperature C

Equation from $T$ vs. In $C_{t} / C_{0}$ plot Linear Correlation

Reaction Rate $1 / \min$

Observations 


\subsection{COLUMN REACTION TEST DATASHEET}

Peroxide Destruction Catalyst Column Reaction Test

Date

Catalyst

Catalyst Amount

Bed Height

gr

Expanded Bed $\mathrm{H}$ in.

in.

Feed Solution

Water Volume

$\mathrm{pH}$

H202 target

$\mathrm{H} 2 \mathrm{O} 2$ conc initial

$\mathrm{H} 2 \mathrm{O} 2$ conc final

L $\mathrm{ppm}$ ppm ppm

Flow Rate $\mathrm{mL} / \mathrm{min}$

Time Lapse to T-0 min after outflow

Configuration Up / Down flow

\begin{tabular}{|c|l|l|}
\hline Time (min) & $\mathrm{H} 2 \mathrm{O} 2$ Conc $(\mathrm{ppm})$ & in $\mathrm{C}_{/} / \mathrm{C}_{0}$ \\
\hline 0 & & \\
\hline & & \\
\hline & & \\
\hline & & \\
\hline & & \\
\hline & & \\
\hline & & \\
\hline & & \\
\hline
\end{tabular}

Temperature C

Equation from $T$ vs. In $C_{t} / C_{0}$ plot Linear Correlation Reaction

Rate $1 / \mathrm{min}$

Observations 


\subsection{CATALYST DURABILITY TEST DATASHEET}

\section{Peroxide Destruction Catalyst Durability Test}

Date

Catalyst

Catalyst Amount

Bed Height

gr

Expanded Bed $\mathrm{H}$ in in.

Feed Solution

Water Volume

$\mathrm{pH}$

$\mathrm{H} 2 \mathrm{O} 2$ target

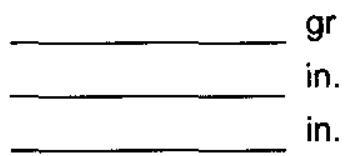

Flow Rate

Time Lapse to T-0 $\mathrm{mL} / \mathrm{min}$ min after outflow

TSS sample interval min starting @ T-0

Temperature C

Observations 